This item was submitted to Loughborough's Research Repository by the author.

Items in Figshare are protected by copyright, with all rights reserved, unless otherwise indicated.

\title{
The imaging of filter cakes through electrical impedance tomography
}

PLEASE CITE THE PUBLISHED VERSION

PUBLISHER

(C) Elsevier

VERSION

AM (Accepted Manuscript)

LICENCE

CC BY-NC-ND 4.0

REPOSITORY RECORD

Tarleton, E.S., and Darryl L. Hancock. 2009. "The Imaging of Filter Cakes Through Electrical Impedance Tomography". figshare. https://hdl.handle.net/2134/4917. 
This item was submitted to Loughborough's Institutional Repository (https://dspace.lboro.ac.uk/) by the author and is made available under the following Creative Commons Licence conditions.

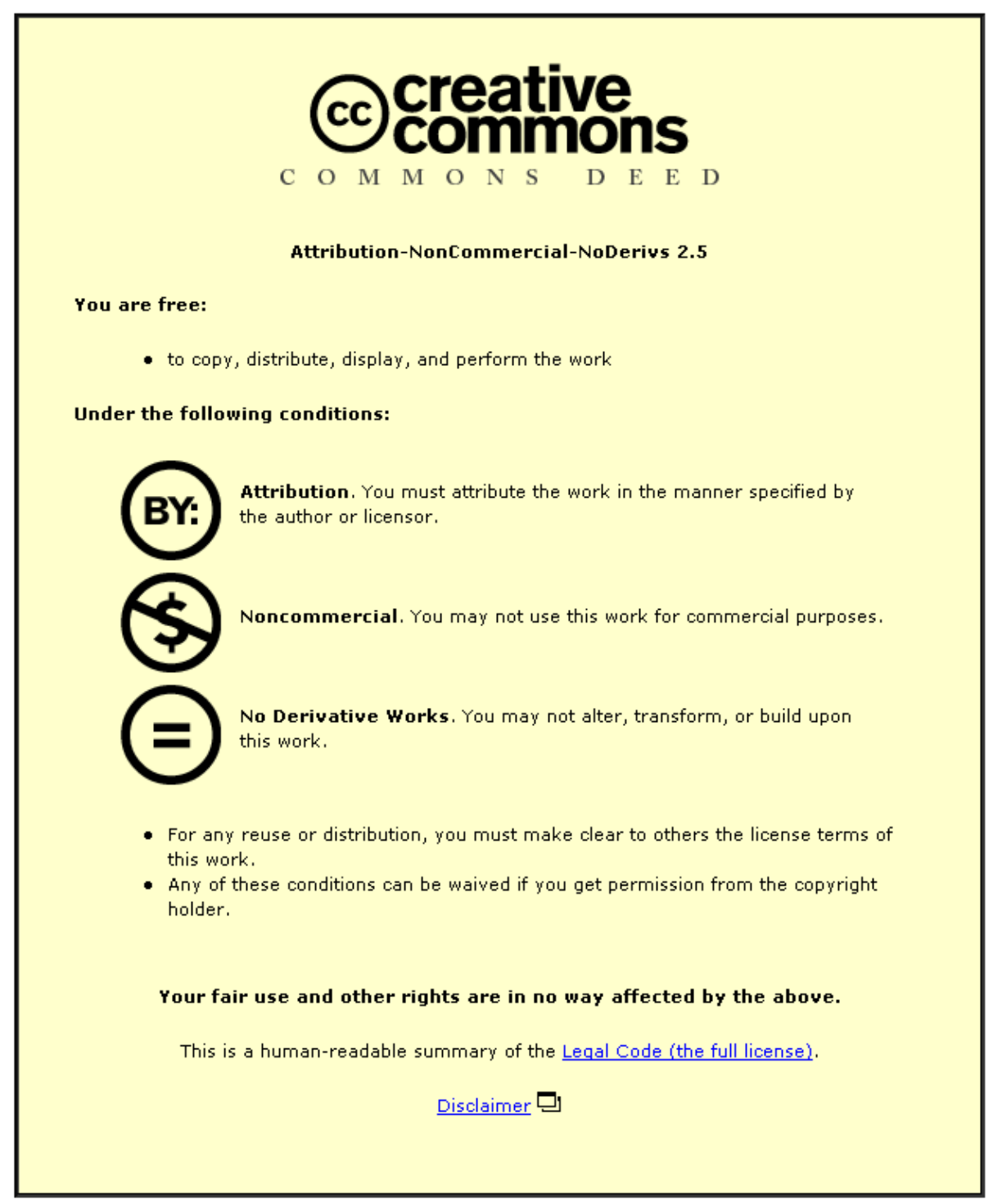

For the full text of this licence, please go to: http://creativecommons.org/licenses/by-nc-nd/2.5/ 


\title{
THE IMAGING OF FILTER CAKES THROUGH ELECTRICAL IMPEDANCE TOMOGRAPHY
}

\author{
E.S. Tarleton (e.s.tarleton@lboro.ac.uk) and D.L. Hancock \\ Department of Chemical Engineering, Loughborough University, Loughborough, Leics., LE11 3TU, \\ UK.
}

\section{SUMMARY}

An experimental rig capable of automatically sequencing and collecting data from a deadend pressure filter is described. The computer controlled apparatus uses electrical impedance measurements in multiple vertical scanning planes to determine the status of a filter cake during either the cake formation, gas dewatering or displacement washing phases of a filter cycle. The data acquired are displayed in real time during a test in conjunction with an indication of liquor flow rates. Initial results from an experimental programme are presented which show the filtration and dewatering characteristics of aqueous based calcium carbonate suspensions. The importance of data acquisition and system control are discussed and an outline of future developments is given.

\section{INTRODUCTION}

The application of tomographic imaging to engineering processes has been a subject of increasing international interest for several years now. Recent publications have shown how a variety of imaging techniques have been applied to interpret processes such as flow in pipelines ${ }^{1}$ and fluid and/or particle motion in fluidised beds, hydrocyclones and stirred tanks ${ }^{2-5}$. However, previous work has failed to (experimentally) investigate in detail the important cake formation, dewatering and washing phases in a sequential filter cycle. As the availability of microprocessor based equipment becomes more widespread such investigations can now feasibly be undertaken using electrical impedance measurements coupled to dedicated computer controlled experimental apparatus.

Electrical impedance, sometimes termed resistance, measurement techniques have previously been used in a relatively limited manner to investigate filter cake formation and cake dewatering ${ }^{6-8}$. The more recent introduction and continuing development of Electrical impedance tomography (EIT) potentially allows more extensive investigations of these and other particulate related processes to be considered. EIT is a soft field technique where the application of an alternating electric field to an array of peripheral electrodes enables the resistivity distribution of an object to be correlated to its concentration. This paper describes initial results from a project which uses the approach of EIT to interpret the progression of the pressure filter cycle. The experimental apparatus is described and data obtained from a cylindrical pressure filter cell fitted with 256 point electrodes show how solids concentration profiles and/or evidence of liquor removal in several vertical planes of a transient filter bed can be obtained.

\section{JUSTIFICATION FOR RESEARCH}

Cake filtration, which relies on the preferential entrapment of particulates upon a semi-permeable medium, is a common form of separation used in most of the chemical process industries. The filter medium is relatively thin and provides the separating surface only at the initial stage(s) of filtration, after which it acts solely as a support to the growing cake. The relationship between filtrate flow rate and the filter cake properties are commonly expressed through a modified form of Darcy's law known as the filtration equation ${ }^{9}$. Whilst this equation is widely used to interpret filtration data, through a 
reciprocal flow rate vs. cumulative filtrate volume plot to give cake permeability and a measure of filter medium resistance, its validity has been questioned on many occasions as it does not take into account all the factors known to influence the separation process. Although cake permeability, and hence specific cake resistance, are quantitative measures of the ease by which a separation can be achieved, their use becomes more difficult when a degree of compressibility exists in the forming cake. Where compressibility is present, cake resistance changes with height throughout the cake and the need to know the relationship becomes more important as the cake compressibility increases. In addition it is recognised that the interactions between the cake and the filter medium can change both the manner in which a filter cake forms and the solids concentration profile obtained therein.

Once a filter cake has been formed upon a separating surface there is frequently the need to post treat it by, for instance, gas dewatering and/or displacement washing. In the former a pressurised gas stream is applied to the top cake surface to force liquor through the cake interstices whilst washing requires the displacing fluid to be a 'clean' liquid. If a simplistic model of straight, uniform capillaries is assumed then the displacing fluid moves through the bed as a uniform front. However, in reality the cake interstices exhibit a tortuous nature whereby a fluid element passing through the structure travels a greater distance than if the structure was formed from parallel capillaries. The value of the tortuosity factor depends upon the path travelled by the fluid element, which in turn, depends upon the structure of the porous medium. As all filter cakes exhibit a degree of tortuosity, the induced dispersion phenomena can become important to the extent that poor dewatering and washing are frequently encountered. Such problems may become extreme when channelling occurs. Here, certain areas of a filter cake exhibit a significantly lower resistance to fluid flow and a high proportion of the displacing fluid preferentially passes through this area resulting in poor post-filtration treatments. Smith et al. ${ }^{10}$ have shown that the irregularly shaped particles commonly encountered in solid/liquid separation introduce an element of randomness to the process of bed formation due to their structural and orientation anisotropy.

The need to understand, acquire and display (real-time) data throughout all phases of the filter cycle are imperative if the phenomena described above are to be understood in the context of solid/liquid separation. The ability to interrogate particle/fluid motions during the separation process is a prerequisite to this as is the ability to provide a test rig which removes as much transient operator interference as possible. Such an approach has been taken in the current work whereby a computer controlled rig capable of taking tomographic scanned images has been constructed and successfully commissioned. This integration of chemical, electrical and computer technology and the initial experimental data acquired from the rig are described below.

\section{EXPERIMENTAL APPARATUS}

The principal hardware for the electrical impedance measurement system comprised a deadend pressure filter cell (illustrated in Figure 1) and its associated electronic circuitry. The filter cell, constructed from stainless steel (s/s), contained 16 (horizontal) rings of electrodes situated at intervals along its length. The first six rings were equi-spaced at $10 \mathrm{~mm}$ intervals above the septum, the next five were spaced at $20 \mathrm{~mm}$ intervals with the final five rings spaced at $30 \mathrm{~mm}$ intervals. Each ring contained 16 electrodes evenly spaced around the periphery of the cell. The 256 point electrodes positioned throughout the cell protruded $5 \mathrm{~mm}$ from the internal wall of the filter cell to prevent tracking of the electrical signal. The cell, capable of operation at internal pressures up to $10 \mathrm{bar}$, had a filtration area of $80 \mathrm{~cm}^{2}$ and was designed, fabricated and tested in accordance with the current British Standard for pressure vessels (BS5500).

Cite paper as: Tarleton E.S. and Hancock D.L., 1996, The imaging of filter cakes through electrical impedance tomography, Filtration and Separation, 33(6), 491-494. Also presented at Filtech Conference, 1995, Karlsruhe, Germany. Paper awarded The Filtration Society Gold Medal, 1997. 
For suitable impedance measurements to be taken each electrode was able to either generate an electrical current (termed pulsed), receive a current (termed earthed) or be neither pulsed nor earthed (termed floating). The co-ordination of the electrodes was performed using a system of CADCAM designed and manufactured printed circuit boards. Referring to Figure 1, a distribution (or master) board and 16 ring (or daughter) boards were developed in conjunction with a mimic display board and two interface circuit boards that allowed data transfer to, and from, a driving computer fitted with PCL$812 \mathrm{G}$ and DVM add-on cards provided by Fairchild ${ }^{\mathrm{TM}}$. A digital signal, supplied to the master/daughter boards, determined which electrodes were switched to the pulsed or earthed states. This procedure allowed an alternating electric current to pass between the chosen pair of electrodes. The current was provided by a $2 \mathrm{kHz}$ square wave form generator having a mark-space ratio of unity. The square wave voltage generated across the filter cell was measured and calibrated (prior to an experiment) to the suspension concentration using a combination of the add-on cards installed in the computer and driving software.

The remainder of the experimental rig comprised two s/s storage vessels, incorporating temperature sensors and stirrers, connected by s/s piping to the filter cell. The vessels stored the feed suspension and wash water respectively. Compressed air at pressures up to 8 bar was supplied to the control valves on the rig pipework and also fed to the storage vessels/filter cell via an electronic regulator such that the driving force for the filtration and cake dewatering/washing phases of the filter cycle was provided. A mimic display panel indicated which electrodes were pulsed and earthed within the filter cell at any one time and a heater/cooling system regulated the temperature of the filter cell and storage vessel contents by continuously passing heating/cooling water through their surrounding jackets. This counteracted any fluctuations in ambient temperature and eliminated temperature transients induced by slurry flow during an experiment. When a washing phase was included in the filter cycle, liquor samples could be taken using a 20 interval rotary table situated directly below the filter cell. An electronic balance also situated below the filter cell enabled liquor transport rates to be continuously monitored and mass balance calculations to subsequently be performed. All components related to data acquisition and rig operation were sequenced by the computer through dedicated computer software. A schematic diagram of the experimental apparatus is shown in Figure 2.

\section{EXAMPLE RESULTS AND DISCUSSION}

The experiments performed thus far with $10 \% \mathrm{v} / \mathrm{v}$ suspensions of calcium carbonate (calcite, $x_{50}=$ $10.16 \mu \mathrm{m}$ ) dispersed in distilled water have shown that data can successfully be acquired during both the filtration and dewatering phases of the filter cycle. The electrical impedance measurements were taken within one vertical plane of the filter cell (i.e. corresponding diametrically opposite electrode pairs were sequentially activated in each horizontal ring) and samples of the results at two different times during the test are shown in Figures 3-6.

Figure 3 shows a solids concentration profile within the filter cell after $140 \mathrm{~s}$ filtration at a constant pressure of $200 \mathrm{kPa}$. Here, the essentially incompressible cake is beginning to form adjacent to the filter medium at a solids concentration in excess of $30 \% \mathrm{v} / \mathrm{v}$; the unfiltered suspension remains at the feed concentration. Figure 4 gives an indication of the time dependency of the solids concentration within the cell; the data-sets portraying the solids concentration for the seven (activated) electrode pairs closest to the filtering surface. It is seen that as the cake progressively grows in height so the measured solids concentrations increase correspondingly. Figures 5 and 6 show data for the same test after $1800 \mathrm{~s}$ have elapsed where the filtration phase of the filter cycle is completed after $1200 \mathrm{~s}$ and the gas dewatering at $200 \mathrm{kPa}$ pressure commences.

Cite paper as: Tarleton E.S. and Hancock D.L., 1996, The imaging of filter cakes through electrical impedance tomography, Filtration and Separation, 33(6), 491-494. Also presented at Filtech Conference, 1995, Karlsruhe, Germany. Paper awarded The Filtration Society Gold Medal, 1997. 
The data in Figure 5 indicate that a reciprocal flow rate vs. cumulative filtrate volume plot yields a straight line for the period of filtration, with the gradient rising sharply when dewatering is initiated; this being in accordance with traditional theory ${ }^{9}$. Figure 6 gives a measure of the liquor content in the filter cake as a function of time for both the filtration and dewatering phases of the cycle. During the filtration phase the concentration of solids within the saturated cake is essentially constant throughout its depth confirming the incompressible nature of the calcium carbonate cake. After $1200 \mathrm{~s}$ have elapsed the apparent solids concentration rises sharply as liquid is removed from the cake by the pressurised displacing gas. In fact the solids concentration is not in excess of $80 \% \mathrm{v} / \mathrm{v}$ at the end of the test, rather the cake structure remains essentially unaltered (i.e. solids concentration is approximately $40 \% \mathrm{v} / \mathrm{v}$ ) and liquid is removed from the particle interstices thereby effectively increasing the solids concentration. This may be confirmed by re-plotting the data to show cake moisture content as a function of time.

Figure 7 gives an example of data extracted from a similar test using a calcium carbonate suspension where the filter cell was scanned over two orthogonal vertical planes. In this instance the data indicate that the cake is forming in a relatively homogeneous manner with little evidence of the formation of preferential flow channels.

Initial filtration experiments with calcium carbonate suspensions have been performed for constant filtration/dewatering pressures over a maximum of two vertical planes. The experimental rig has the capability to display information in real-time for up to 8 distinct vertical planes for any combination of filtration, dewatering and washing phase(s) in addition to a 'live' display of liquor flow rate on a reciprocal flow rate/cumulative volume graph. Moreover, the potential exists to provide for full tomographic scanning using any of the recognised Neighbouring, Opposite, Multi-reference or Adaptive methods. By automatically controlling the rig it is also technically feasible to perform experiments at conditions of constant flow rate and variable pressure/variable flow rate with little additional effort and potentially mimic any pump which might be used to initiate a separation. The development of such technologies can only assist the development of ongoing modelling/simulation work $^{11,12}$.

\section{CONCLUSIONS}

The now widespread availability of microprocessor based equipment such as computers, controllers, transducers and sequencers opens many new avenues of research in solid/liquid separation. The ability to monitor and control a process and display information in real time provides a great incentive to researchers to devise new and novel methods of experimentation. This integration of mechanical design, electronics and computer control with chemical engineering might be termed 'chematronics' and its application will undoubtedly forward research for many years to come.

\section{ACKNOWLEDGMENT}

The authors would like to express their thanks to the Engineering and Physical Science Research Council for the receipt of studentship 93310653 to expedite the current research.

\section{REFERENCES}

1. C.G. Xie, S.M. Huang, B.S. Hoyle, R. Thorn, C. Lenn, D. Snowden and M.S. Beck, IEEE Proceedings-G, 139, 89, 1992.

Cite paper as: Tarleton E.S. and Hancock D.L., 1996, The imaging of filter cakes through electrical impedance tomography, Filtration and Separation, 33(6), 491-494. Also presented at Filtech Conference, 1995, Karlsruhe, Germany. Paper awarded The Filtration Society Gold Medal, 1997. 
2. A. Boniface, Chemical Engineer, $\mathbf{2 6}^{\text {th }}$ July, 14, 1990.

3. D. Mewes and W. Ostendorf, Int. Chem. Eng., 26(1), 11, 1986.

4. T. Dyakowski, R.A. Williams and M.S. Beck, $1^{\text {st }}$ International Particle Technology Forum, pp.24-29, AIChE, Denver, Colorado, August 1994.

5. F.J. Dickin, R.A. Williams and M.S. Beck, Chem. Eng. Sci., 48, 1883, 1993.

6. R.G. Holdich, E.S. Tarleton and F.J. Shaw, Proc. Filtech Conference, pp.11-20, The Filtration Society, Karlsruhe, Germany, October 1993.

7. A. Vince, PhD Thesis, University of Exeter, 1985.

8. S.A. Willmer, E.S. Tarleton and R.G. Holdich, Proc. Filtech Conference, The Filtration Society, Karlsruhe, Germany, October 1995.

9. D.R. Sperry, Met. Chem. Eng., 15, 198, 1916.

10. W.O. Smith, P.D. Foote and P.F. Busang, Phys. Rev., 34, 1271, 1929.

11. R.J. Wakeman and E.S. Tarleton, Min. Eng., 7(11), 1411, 1994.

12. R.J. Wakeman and E.S. Tarleton, Filt. Sep., 27(6), 412, 1990. 


\section{FIGURES AND TABLES}

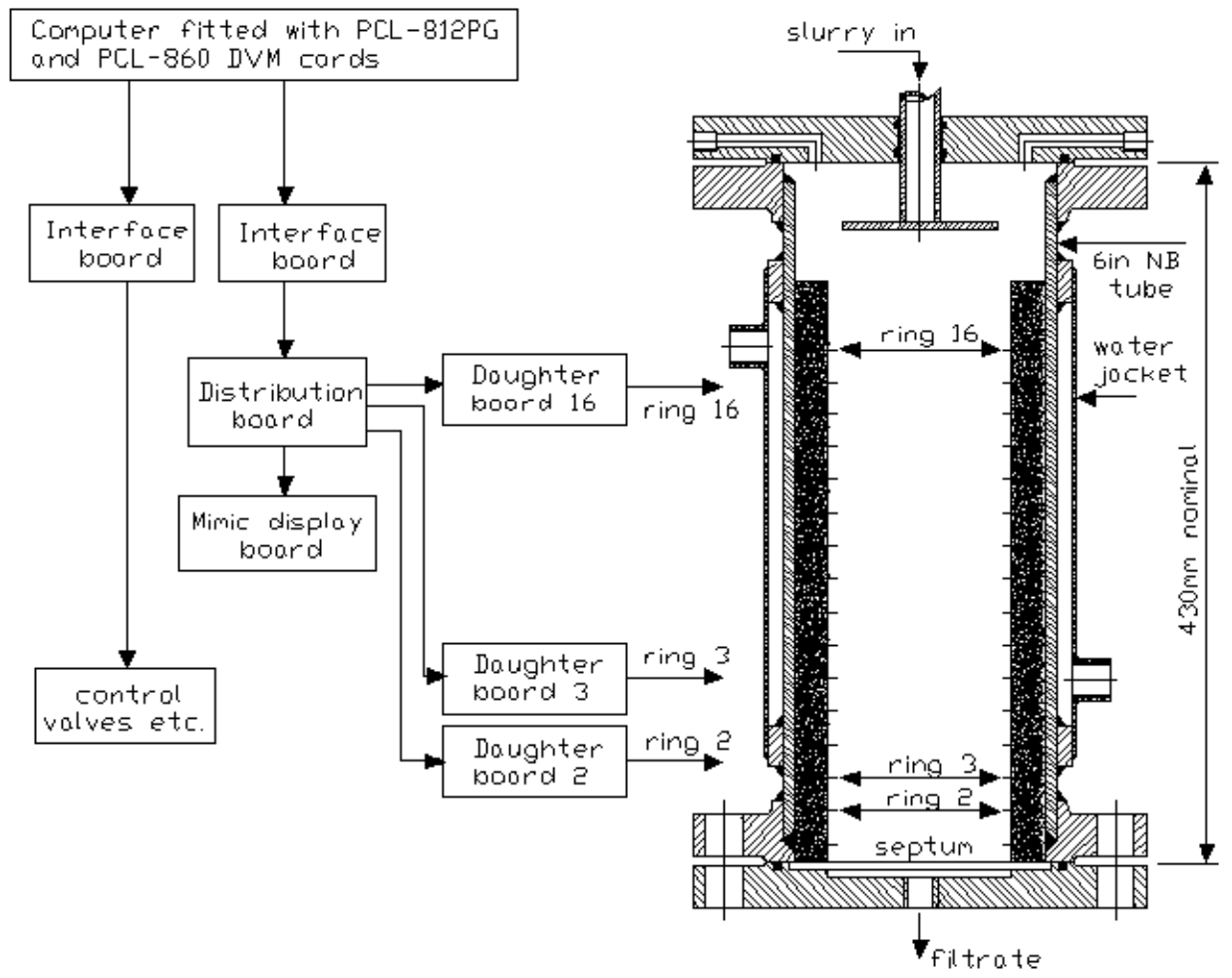

Figure 1: The pressure filter cell showing construction, critical dimensions and a schematic of the electrode control system. 


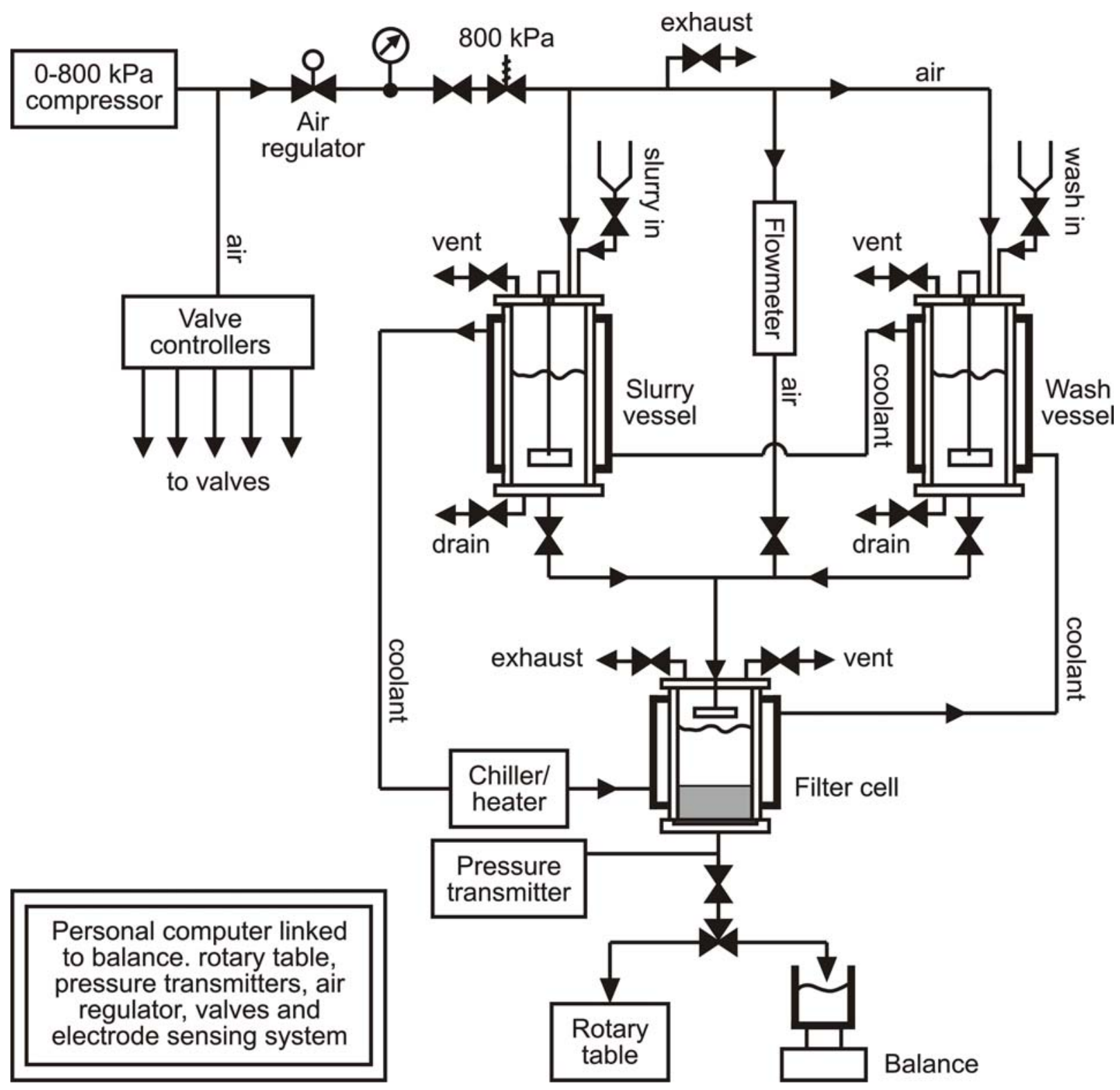

Figure 2: Schematic representation of experimental apparatus. 


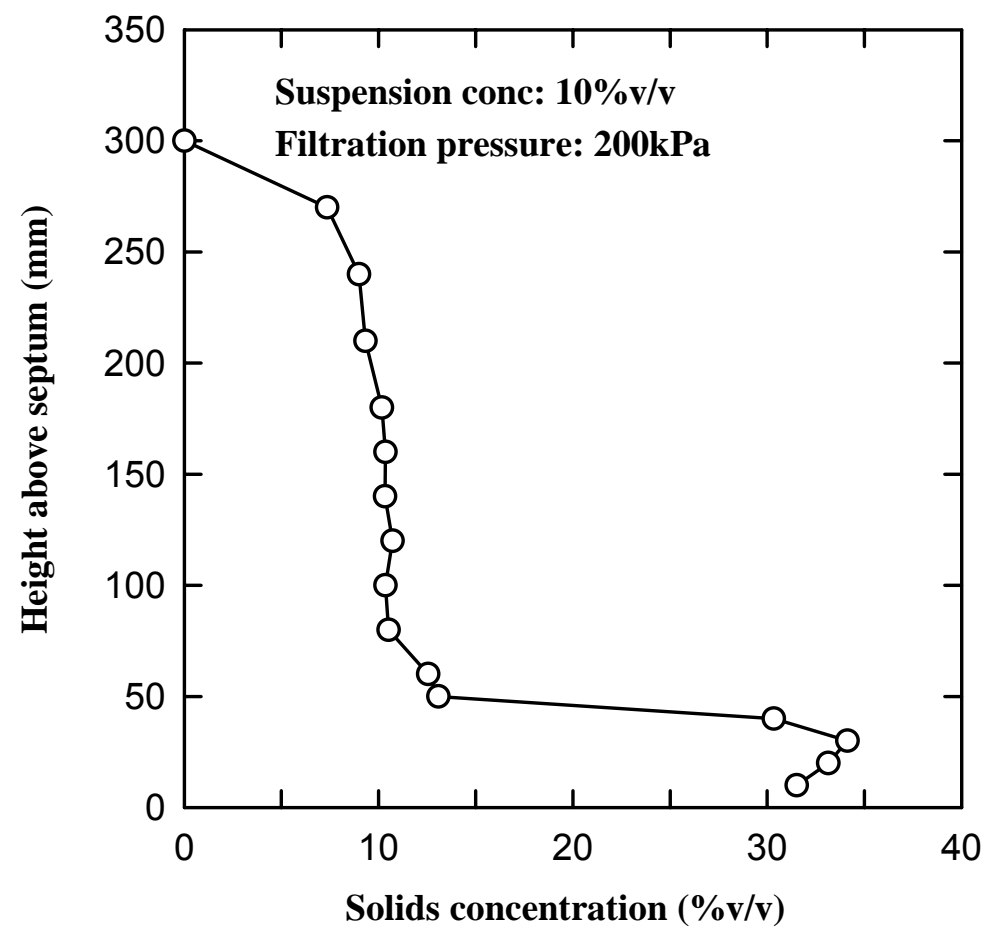

Figure 3: Solids concentration profile in filter cell after $140 \mathrm{~s}$ filtration.

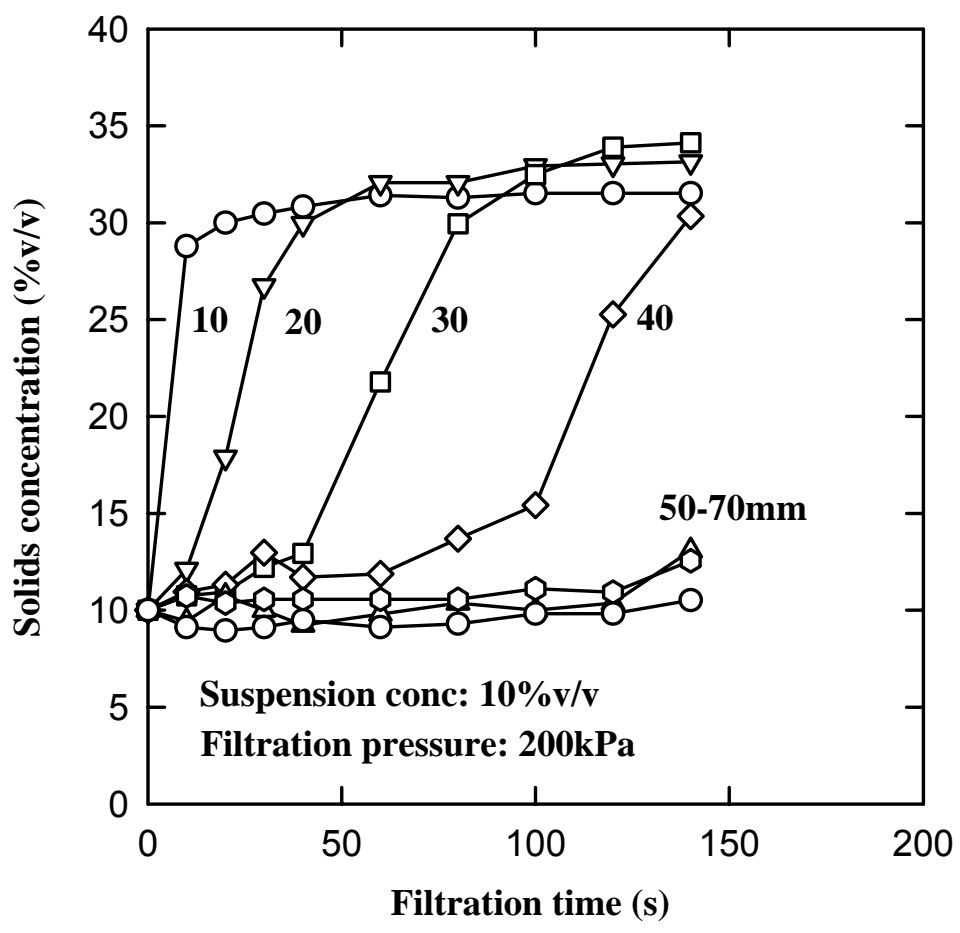

Figure 4: Solids concentration history up to $70 \mathrm{~mm}$ from filter medium (after $140 \mathrm{~s}$ ). 


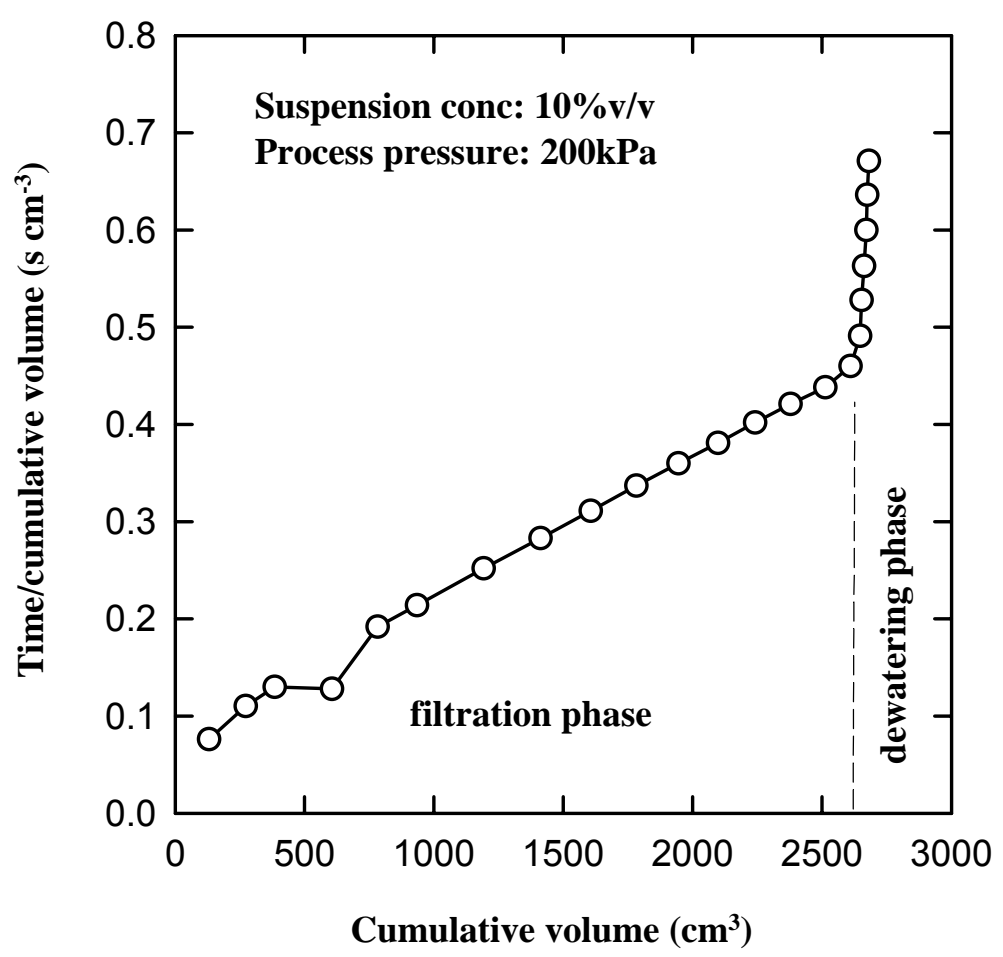

Figure 5: Reciprocal flow rate vs. cumulative volume plot after $1800 \mathrm{~s}$ of filtration/gas dewatering.

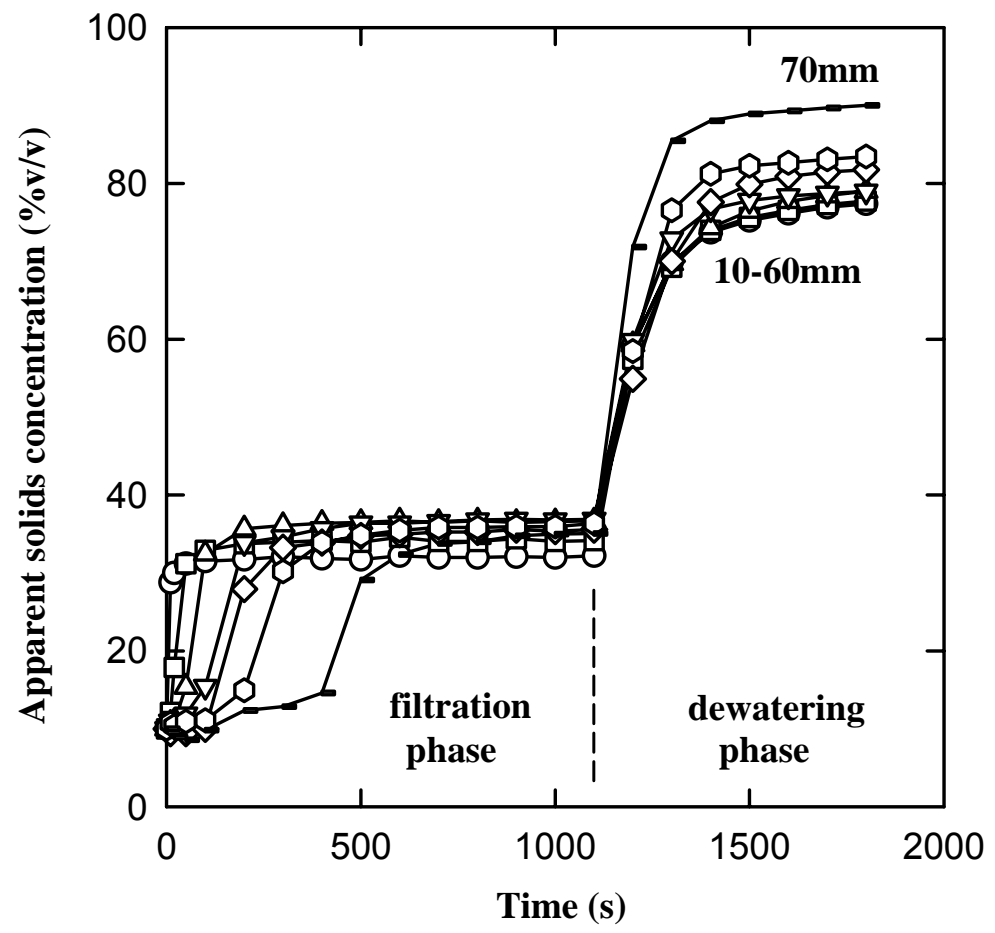

Figure 6: Solids concentration history up to $70 \mathrm{~mm}$ from filter medium (after $1800 \mathrm{~s}$ ). 


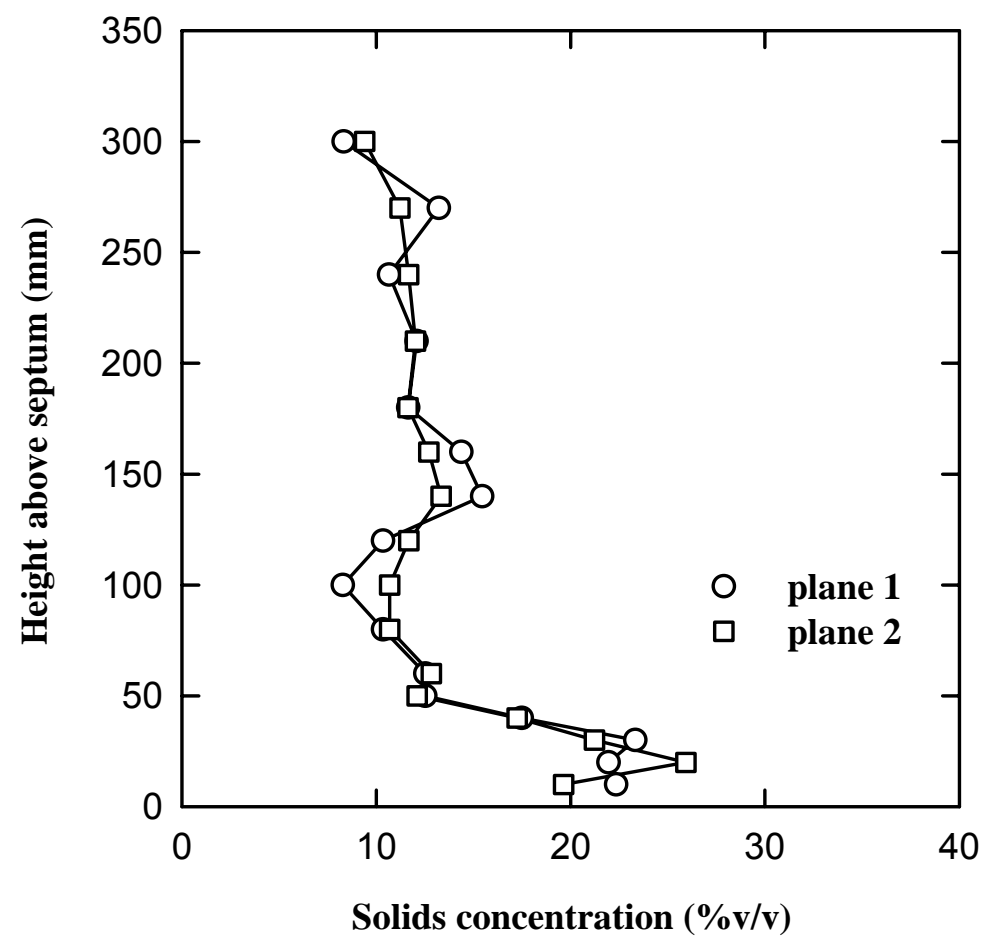

Figure 7: Solids concentration in two orthogonal planes after $120 \mathrm{~s}$ filtration. 